\section{Commentary: Three-dimensional printing and customizable implants: The future is now}

\author{
Benny Weksler, MBA, MD
}

The principles of reconstruction of the chest wall after resection include providing adequate replacement for chest wall rigidity and proper coverage of any prosthetic material. Chest wall defects larger than $5 \mathrm{~cm}$ often require a rigid or a semirigid prosthesis to restore chest wall integrity. Over the years, many different autologous and synthetic materials have been used to reconstruction the chest wall. ${ }^{1}$ Commonly, a synthetic mesh is used to provide some rigidity and cover the defect. The most common materials used are polypropylene and polytetrafluoroethylene. ${ }^{2}$ Another option, which was popularized by the Memorial Sloan-Kettering group and provides more rigidity to the chest wall, is the use of a "methyl-methacrylate sandwich mesh." Although both methods work well to provide coverage and rigidity, cosmetic results are often below accepted standards. The introduction of 3-dimensional (3D) printing for medical purposes generated significant interest in custom-made prostheses for a variety of reconstructive purposes, including the chest wall. ${ }^{4}$ There are clear advantages to a personalized prosthesis, created to cover specific defects, that restores rigidity, function, and cosmesis to the chest wall.

In the present issue of JTCVS Techniques, Ahmed and colleagues ${ }^{5}$ present 2 patients who required extensive chest wall resection for chondrosarcoma. ${ }^{5}$ The chest wall of each patient was reconstructed using a customized, prefabricated, porous polyethylene implant. The implants were printed by an outside company based on preoperative imaging and the planned surgical margins. When implanting the

\footnotetext{
From the Division of Thoracic and Esophageal Surgery, Department of Thoracic and Cardiovascular Surgery, Allegheny General Hospital, Pittsburgh, Pa.

Disclosures: B.W. is a Proctor for Intuitive Surgery and Speaker for AstraZeneca.

The Journal policy requires editors and reviewers to disclose conflicts of interest and to decline handling or reviewing manuscripts for which they may have a conflict of interest. The editors and reviewers of this article have no conflicts of interest.

Received for publication May 10, 2021; revisions received May 10, 2021; accepted for publication May 11, 2021; available ahead of print May 14, 2021.

Address for reprints: Benny Weksler, MBA, MD, Thoracic and Cardiovascular Surgery, Allegheny General Hospital, 320 E. North Ave, 14th Fl, South Tower, Pittsburgh, PA 15212 (E-mail: benny.weksler@ahn.org).

JTCVS Techniques 2021;8:216-7

2666-2507

Copyright (C) 2021 The Author(s). Published by Elsevier Inc. on behalf of The American Association for Thoracic Surgery. This is an open access article under the CC BY-NC-ND license (http://creativecommons.org/licenses/by-nc-nd/4.0/).

https://doi.org/10.1016/j.xjtc.2021.05.006
}

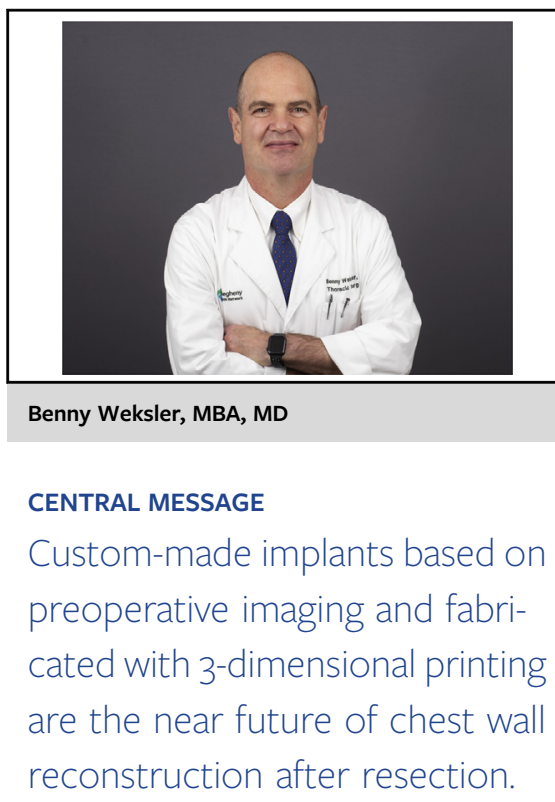

prosthesis, a mold was used to assist the surgeon with obtaining the planned resection margins, and the template copy of the final prosthesis was used to ascertained proper fit before implantation. The prosthesis was secured using cortical screws to adjacent ribs, although it could also be sutured to muscle and fascia.

Despite the complexity of the 3-D printing and the fact that the provider of the prosthesis was not on the same continent as the authors, the turnaround time was less than 1 month. The cost of the prosthesis was high, but perhaps not exorbitant, at $\sim \$ 11,000$ US. The authors state that the material allows for tissue ingrowth, and some studies in rodents corroborate this assumption. However, there are no studies in humans showing clear tissue ingrowth with this type of prosthesis, and recent experience with tissue replacement in humans supports some skepticism of this claim. However, even without tissue ingrowth, I like the way that the prosthesis was fabricated, the short turnaround time, and the reasonable cost. I would encourage the reader to watch the video by $\mathrm{Dr}$ Ahmed that accompanies the article, where he explains the technique and the material in some detail.

Several different materials have been used in 3-D printing prostheses for chest wall replacement. Titanium implants are relatively popular; however, they are expensive to manufacture and cannot be easily adjusted. ${ }^{6}$ Titanium also does not allow for easy suturing to muscle or soft tissue. Polyether ether ketone implants are another 
interesting option. Recently, Wang and colleagues ${ }^{7}$ reported on their experience with 18 patients who had chest wall resection and reconstruction using 3-D printing to create polyether ether ketone prostheses with excellent results. Each implant took only 30 hours on average to fabricate inclusive of surgical planning, designing the prosthesis, 3-D printing, and processing before implantation.

Evolution in applied materials and cheaper 3-D printing will open a new era in reconstruction of the human body. I believe that within a relatively short time thoracic surgeons will have new and varied options to personalize resection and reconstruction of the chest wall. The use of generic mesh or methyl-methacrylate for chest wall reconstruction will likely be fondly remembered by some but not missed by most.

\section{References}

1. McCormack PM. Use of prosthetic materials in chest-wall reconstruction: assets and liabilities. Surg Clin N Am. 1989;69:965-76.

2. Deschamps C, Tirnaksiz BM, Darbandi R, Trastek VF, Allen MS, Miller DL, et al Early and long-term results of prosthetic chest wall reconstruction. J Thorac Cardiovasc Surg. 1999;117:588-91; discussion 591-2.

3. Suzuki K, Park BJ, Adusumilli PS, Rizk NP, Huang J, Jones DR, et al. Chest wall reconstruction using a methyl methacrylate neo-rib and mesh. Ann Thorac Surg. 2015;100:744-7.

4. Malik HH, Darwood AR, Shaunak S, Kulatilake P, El-Hilly AA, Mulki O, et al Three-dimensional printing in surgery: a review of current surgical applications. J Surg Res. 2015;199:512-22.

5. Ahmed ADB, Prakash PS, Chia CML. Customized 3-dimensional printed rib plating in chest wall reconstruction. J Thorac Cardiovasc Surg Tech. 2021;8: 213-5.

6. Kamel MK, Cheng A, Vaughan B, Stiles B, Altorki N, Spector JA, et al. Sternal reconstruction using customized 3D-printed titanium implants. Ann Thorac Surg. 2020;109:e411-4.

7. Wang L, Huang L, Li X, Zhong D, Li D, Cao T, et al. Three-dimensional printing peek implant: a novel choice for the reconstruction of chest wall defect. Ann Thorac Surg. 2019;107:921-8. 